\title{
TABLE DES MATIÉRES.
}

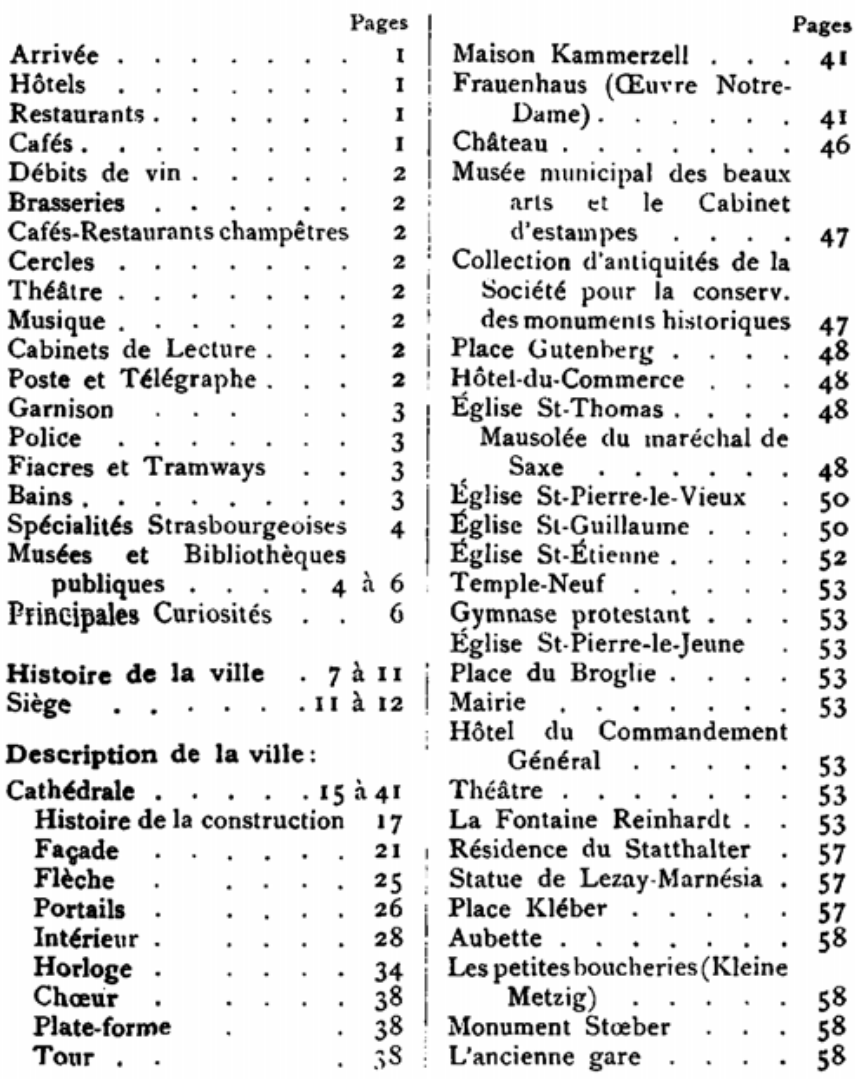




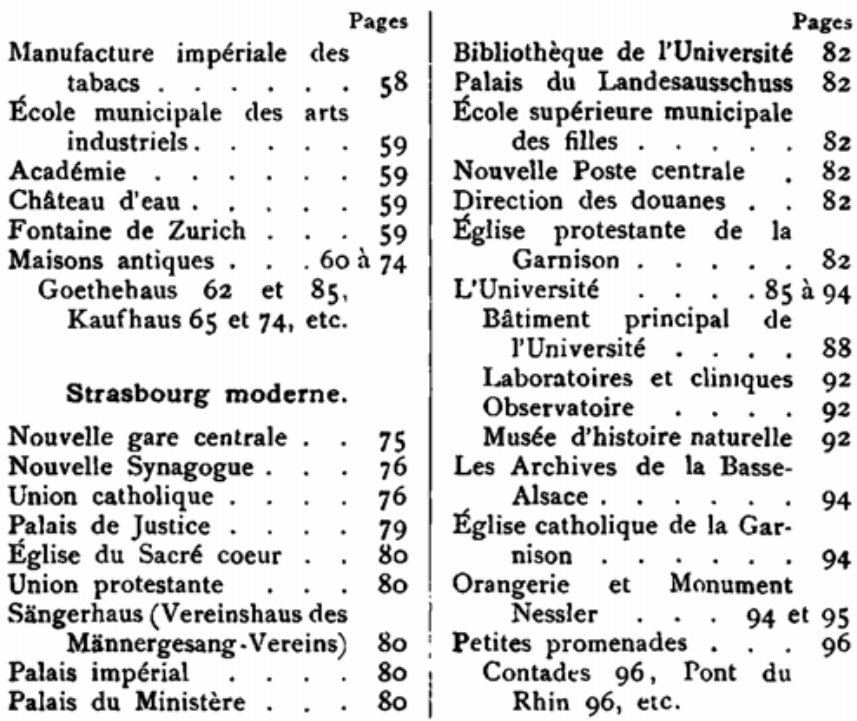




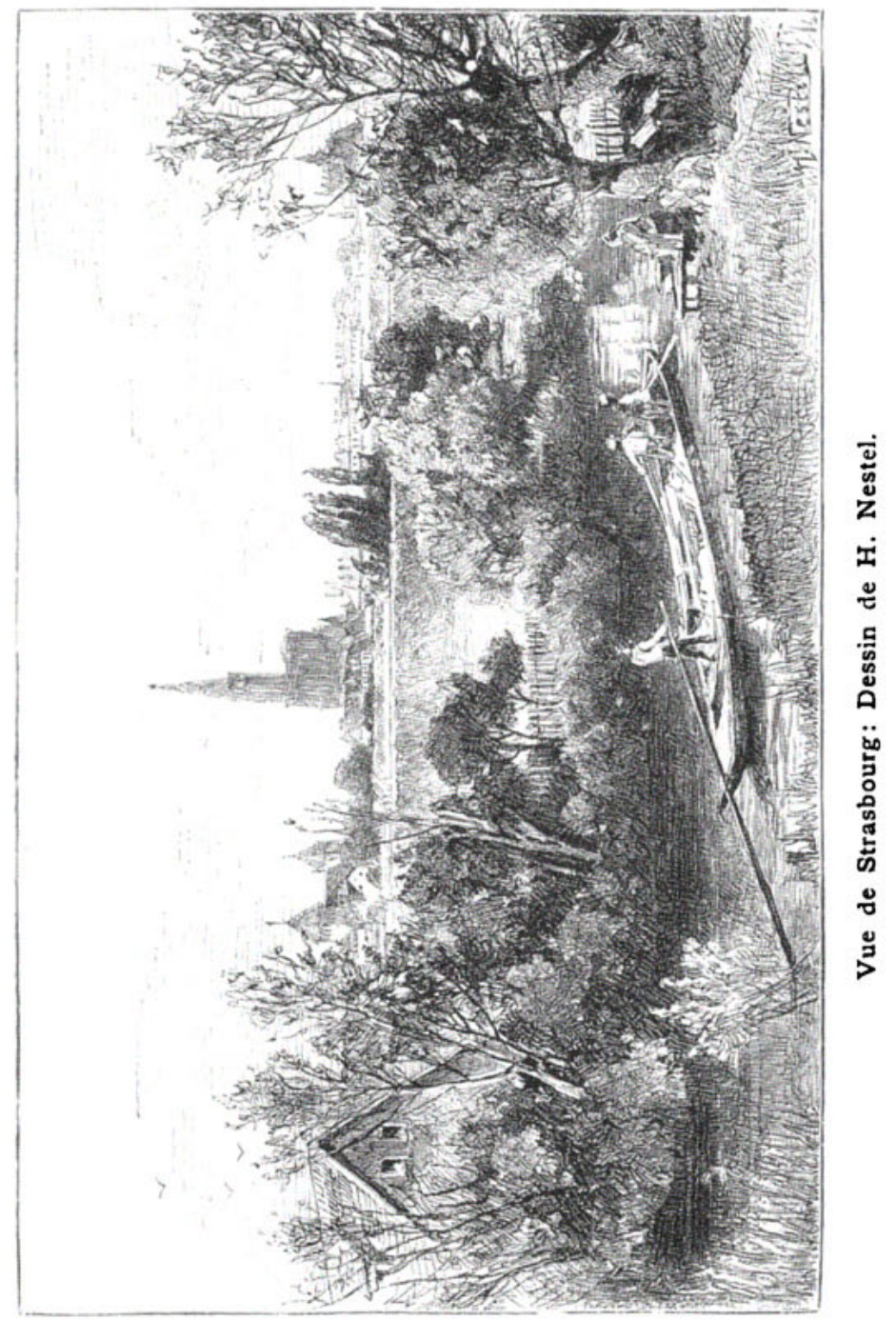




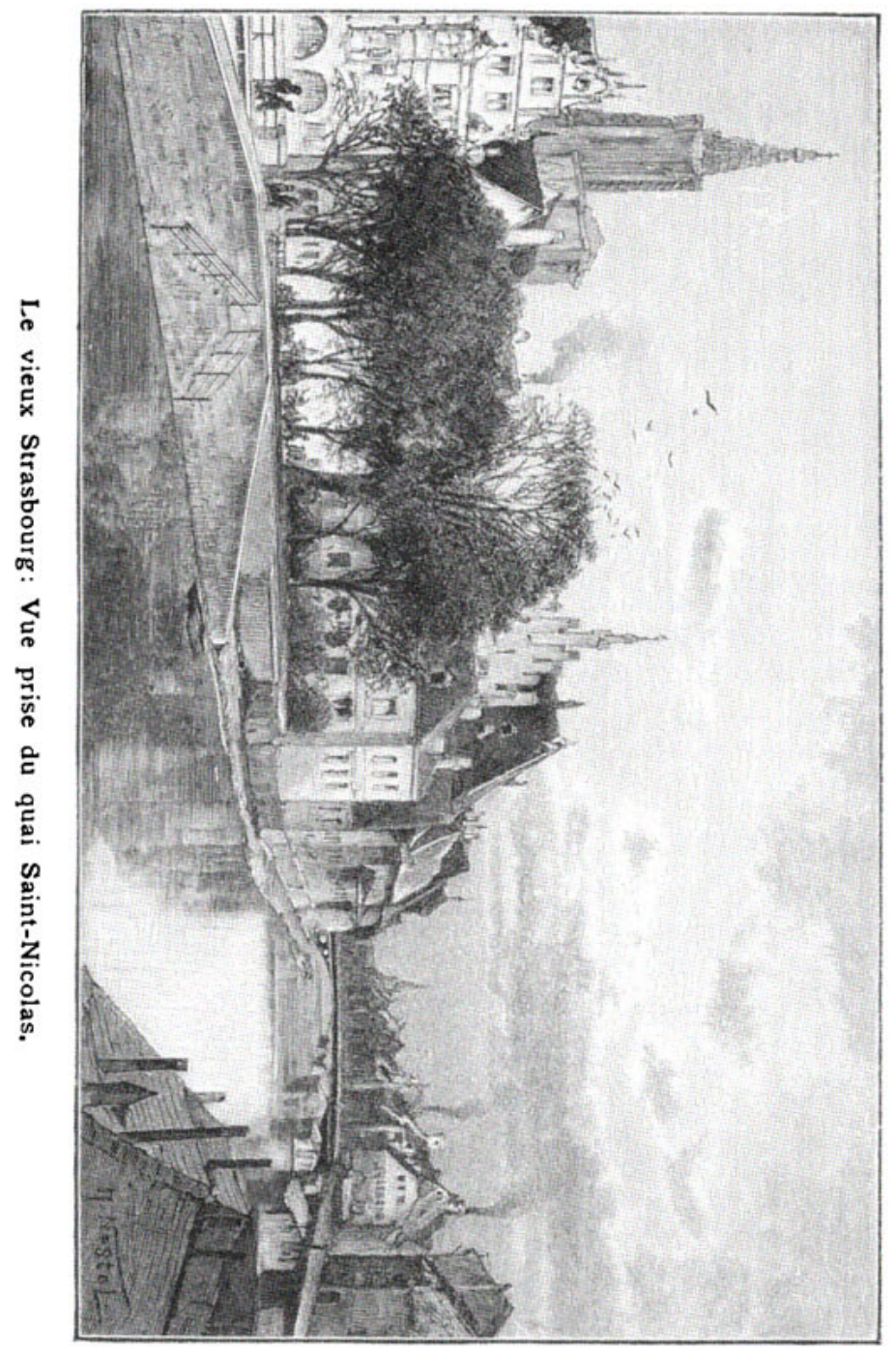

